\title{
Tecnologia Assistiva: Uma Proposta de Inclusão das Pessoas com Deficiência nas Escolas Públicas Regulares ${ }^{1}$
}

Arnaud Soares de Lima Junior - Universidade do Estado da Bahia arnaudjr@terra.com.br. Erí Santana - Universidade do Estado da Bahia eri@pontodanet.com.br

\begin{abstract}
Resumo: Esta pesquisa reflete um estudo para oferecer possibilidades de acesso às pessoas com deficiência nas escolas públicas regulares a partir do uso das tecnologias assistivas, que dentro de uma abordagem humanista, possuem potencialidades para criarem ambientes e processos acessíveis de aprendizagem. A pesquisa se desenvolveu a partir de uma metodologia de Pesquisa-Ação Integral, com o envolvimento de todos, para buscar soluções e fazer uma intervenção no processo de inclusão educacional e social das pessoas com deficiência. O estudo foi operacionalizado com a formação de uma equipe multidisciplinar para discussões, o que permitiu uma visão sistêmica e complementar dos problemas, e com um levantamento das pessoas com deficiência no município, para criar estratégias e prioridades nas ações. Tendo como principais resultados, a implantação do Centro de Pesquisa de Tecnologias Assistivas, a inclusão de Libras como segunda língua no currículo do Ensino Fundamental I e II, reestruturação arquitetônica dos laboratórios de informática, e a formação permanente de um grupo de pesquisa multidisciplinar incluindo representantes das áreas de Educação, Saúde, Social, Obras, Comunidade Civil, pessoas com deficiência e familiares, e Câmara Legislativa.
\end{abstract}

Palavras-chave: inclusão, tecnologia assistiva, pessoas com deficiência.

Assistive Technology: A Proposal for Inclusion of People with Disabilities in Regular Public Schools.

Abstract: This research reflects a study to provide access opportunities for people with disabilities in regular public schools through the use of assistive technologies, which within a humanistic approach, have the potential to create accessible environments and processes of learning. The research grew out of a methodology for Integral Action Research, with the involvement of all to find solutions, and make an intervention in the process of educational and social inclusion of people with disabilities. The study was operationalized with the formation of a multidisciplinary team for discussions, which allowed a systemic and complementary of the concerns, and a survey of disabled people in the city to create strategies and prioritize actions. Having as its main achievements, the implementation of the Centre for Research on Assistive Technologies, the inclusion of Libras as a second language in the curriculum of elementary school I and II, architectural restructuring of computer labs and training of a multidisciplinary research group including representatives from areas of Education, Health, Social Work, Community, Civil, people with disabilities and their families, and the Legislative Chamber.

Keywords: inclusion, assistive technology, people with disabilities.

\footnotetext{
${ }^{1}$ Pesquisa financiada pela prefeitura municipal de Madre de Deus - Bahia
} 


\section{Introdução}

A presença das tecnologias de comunicação e informação (TIC) nas escolas se evidencia a partir dos resultados de uma relação prática com as condições concretas dos alunos e dos profissionais da educação na estrutura social, isto é, ela é vista no sistema educacional através de uma nova lógica com novas relações, novas linguagens e novos interesses dos seus sujeitos, dentro de uma relação educacional não formal. Isto não significa que as forças macro de interesses do sistema, que aqui podemos considerar como o Estado e elites econômicas (Boneti, 2007: 13-14), não manipulem esta dinâmica. As dificuldades para materialização das políticas públicas que possibilitariam uma reversão no sistema educacional se apóiam também nas condições sociais que não viabilizam os meios necessários para a elaboração adequada às novas idéias que surgem com os movimentos sociais e participação de representantes das comunidades nas decisões políticas.

Trazer o uso das tecnologias assistivas (TA) dentro de uma proposta de inclusão das pessoas com deficiência nas escolas públicas regulares, requer muito mais do que exigir Leis, Decretos e Resoluções. É necessária uma mudança da estrutura social e esperar uma implicação de todos na mudança. Nesta perspectiva, o MEC através da Secretaria de Educação Especial traz a Política Nacional de Educação Especial na Perspectiva da Educação Inclusiva ${ }^{1}$ para acompanhar os avanços do conhecimento e das lutas sociais, visando constituir políticas públicas promotoras de uma educação de qualidade para todos os alunos. Porém, em muitos momentos, mesmo com a instituição do processo, as mudanças na prática não acontecem. Arendt (2006: 35) adverte a esse respeito, ao tratar dos processos políticos:

Se se quer mudar uma instituição, uma organização ou entidade pública existente no mundo, então só se pode renovar sua constituição, suas leis, seus estatutos e esperar que tudo mais se produza por si mesmo.

Esse "esperar que tudo mais se produza por si mesmo" é o humano que acontece no espaço onde os homens se agrupam e desenvolvem política, e está relacionado com a subjetividade destes sujeitos e suas relações de força e que Arendt (2008: 195) chama de mediação subjetiva, que não pode se materializar e não é tangível, mas existe e está vinculada ao mundo objetivo, formando a esfera dos negócios humanos, a "teia de relações humanas”.

Um aspecto importante na efetivação da inclusão das pessoas com deficiência refere-se à necessidade de ampliar e socializar as reflexões sobre este processo, já que esta instância supõe engajamento, implicação, correlação de forças e produção de conhecimento específico sobre a problemática. Outro aspecto é a necessidade de autonomia e de liberdade das pessoas com deficiência para participarem do processo de definições das políticas de inclusão. A Declaração Universal dos Direitos das Pessoas com Deficiência, em 2001, lança o princípio básico para desenvolver ações de inclusão das pessoas com deficiência: "Nada sem eles, para eles”. Isto implica que as políticas públicas para inclusão das pessoas com deficiência não devem ser elaboradas e nem aprovadas e executadas sem a participação efetiva das pessoas com deficiência.

Nas últimas décadas, a difusão dos movimentos para a inclusão das pessoas com deficiência pelas políticas internacionais como a Declaração de Educação para Todos, a Declaração de Salamanca e a Declaração de Madri; e nacionais: a Constituição Federal de 1988, o capítulo V da LDB, Decreto 3.298, Decreto 3.956 e o Decreto 5.296 de 2 de 
dezembro de 2004 e a Resolução CNE/CEB n 2 de 2001 não produzem resultados práticos na mesma proporção. O Censo Escolar realizado pelo MEC/SEESP registra uma evolução nas matrículas de 1998 para 2006 como resultado das ações e políticas de educação inclusiva nesse período, com um crescimento de $146 \%$ das matrículas nas escolas públicas, que alcançaram 441.155 alunos em 2006, porém este crescimento ainda é quantitativo e não traz a questão da permanência destes alunos nas escolas.

O Instituto Brasileiro de Geografia e Estatística (IBGE), apresenta que as pessoas com deficiência são quase $14,5 \%$ da população brasileira, o que representa aproximadamente 25 milhões de pessoas, número que cresce a cada ano, por três fatores: pela expectativa de vida; pela violência urbana e pela violência no trânsito. Isto nos mostra a necessidade de desenvolver pesquisas que possam diminuir a distância entre o discurso e a ação para a inclusão das pessoas com deficiência nas escolas públicas regulares e nas comunidades, se queremos uma sociedade mais justa, democrática e, portanto, inclusiva.

As TIC não representam apenas um conjunto de ferramentas e métodos, mas uma composição simbólica que atua no desejo e na subjetividade, acrescentando aí os aspectos econômico, social, cultural, psicológico (Lima Jr, 2005). Por estas características, as TIC estão de forma costurada na complexa rede de inclusão das pessoas com deficiência.

Esta perspectiva tecnológica que Lima Jr adotou ao tratar das TIC é utilizada neste trabalho como base para compreensão das TA e de seu papel no processo de inclusão das pessoas com deficiência, pois na base, trata-se de um processo tecnológico específico e que tem seus aspectos político, social e cultural, além do instrumental. Esta premissa das potencialidades das TIC para atendimento da diversidade escolar nos conduziu para procurar entender como as TA podem auxiliar nos esforços que viabilizam o processo de inclusão das pessoas com deficiência. Esta preocupação surgiu a partir do impositivo legal que trouxe as pessoas com deficiência às escolas regulares e com isto, as necessidades de adequações foram evidenciadas, conduzindo à busca de alternativas que permitissem a presença das pessoas com deficiência no ambiente escolar, participando verdadeiramente do processo educacional.

No Brasil já existe um avanço nas Leis e recomendações no processo de inclusão das pessoas com deficiência nas escolas regulares, entretanto a materialização, ainda não aconteceu. Para Montoan (2006: 27) o artigo 208 do capítulo III da constituição o termo "preferencialmente" refere-se a "atendimento educacional especializado" e isto inclui “...o ensino da língua brasileira de sinais (Libras) e do código braile e o uso de recursos de informática e de outras ferramentas e linguagens que precisam estar disponíveis nas escolas ditas regulares”. (Montoan, 2006: 27). Mas, pouco se sabe da implantação de uma escola inclusiva. Segundo Sassaki (2006: 27) o conceito de inclusão começou a ser debatido a partir de 1981, mas na prática são poucas as escolas que conseguem incluir as pessoas com deficiência. Outro grave problema verificado na realidade educacional é a questão das TIC introduzidas nas escolas dentro dos últimos anos não têm as características que as fariam acessíveis para todos, especialmente aqueles com dificuldades motoras, sensoriais e cognitivas.

\section{Tecnologia Assistiva}

Assumindo a perspectiva crítica de tecnologia, parafraseando Lima Jr. (2005) e Arendt (2008), podemos dizer que TA tanto refere-se a dimensão instrumental da produção e utilização de suportes materiais potencializadores ou substitutivos de 
habilidades e faculdades humanas, como o processo crítico, criativo, transformativo mais amplo voltado para a inclusão social e legitimação dos direitos humanos das pessoas com deficiência. Igualmente, também se refere aos usos criativos e transformadores das bases instrumentais instaladas, vez que sua mera disponibilização não garante automaticamente que sejam utilizadas com a intenção política de incluir e transformar situações sociais de desigualdade.

Situamos as TA nessa discussão para analisar sua posição ideológica e seus sentidos constituídos dentro dos contextos em que é utilizada, a partir de uma memória ${ }^{2}$. Para Santos (2009: 23) "As técnicas são oferecidas como um sistema e realizadas combinadamente através do trabalho e das formas de escolha dos momentos e dos lugares de seu uso". As TA assim, respondem a um momento e um lugar de necessidade de uso das TIC.

Nos Estados Unidos, entre 1973 e 1998, várias leis foram criadas para proporcionar qualidade de vida às pessoas com deficiência. Dentro deste período houve um amadurecimento nos conceitos de "acesso" e "inclusão" que demandou a procura de alternativas, chegando à utilização das TIC, para promover o acesso das pessoas com deficiência às escolas, aos meios de comunicação, ao lazer, à saúde. TA é um termo que surgiu para legalizar e instituir as TIC neste lugar, além de prover os recursos financeiros.

A ADA (American With Desabilities Act) ${ }^{3}$, conjunto de leis que regulamentam os direitos das pessoas com deficiência, define TA como recursos e serviços criados para proporcionar mobilidade, independência e bem-estar às pessoas com deficiência. Recursos no texto da ADA são "todo e qualquer item, equipamento ou parte dele, produto ou sistema fabricado em série ou sob medida, utilizado para aumentar, manter ou melhorar as capacidades funcionais das pessoas com deficiência”. E serviços são "aqueles que auxiliam diretamente uma pessoa com deficiência a selecionar, comprar ou usar os recursos acima definidos”.

A norma internacional ISO-9999 junto com a correspondente européia EN29999 traz a definição de TA como:

Qualquer produto, instrumento, equipamento ou sistema técnico usado por uma pessoa idosa ou com deficiência, feito especialmente ou existindo no mercado, destinado a evitar, compensar, aliviar ou neutralizar a dificuldade, incapacidade ou deficiência. (Project D3402 EUSTAT Deliverable D03.2 p. 16)

Os recursos e serviços desenvolvidos estão materializando o desejo de liberdade necessário a todo sujeito. O conceito de TA vai além da definição dos seus recursos e serviços e, por isto, cria margens para várias terminologias como "ajudas técnicas", "tecnologia de apoio”, “tecnologia adaptativa”, e "adaptações”. O próprio termo “Assistiva” é uma palavra que mostra a ideologia de quem no momento da definição exercia o que Santos (2007: 29) vai chamar de "mais-valia” ${ }^{4}$ logo, uma perspectiva médica. Pois, foi nesta área que ela primeiramente se desenvolveu, com o estudo de próteses e procedimentos para reabilitação das pessoas com deficiência. Para Marquezan (2009: 68) “As primeiras produções teóricas sobre o sujeito deficiente foram realizadas por médicos. Daí, a vinculação histórica do sujeito deficiente com a área médica”. Ora, se as tecnologias têm a ver com a criação, logo, essa transformação e criação vão surgir a partir das necessidades de onde elas são criadas, e serão usadas e desenvolvidas dentro de seus interesses, o que justifica o grande desenvolvimento das TA na área médica, que tem o objetivo de adaptar o sujeito para viver na comunidade. 
Vê-se aqui que a lógica médica é adaptar o sujeito para viver nas novas condições, e não, modificar os ambientes e as condições para receber as pessoas com deficiência.

A transposição desta lógica para a área educacional foi uma das grandes barreiras construídas dentro da escola e que impediram o desenvolvimento do processo inclusivo das pessoas com deficiência nas escolas públicas regulares, e ainda hoje dificulta a compreensão das TA como uma proposta para inclusão das pessoas com deficiência. Visto que, a lógica do uso das TA diverge da lógica médica. Ela implica uma mudança da escola na estrutura física, na metodologia, na disponibilidade de recursos, no currículo e na mudança atitudinal para receber as pessoas com deficiência.

\section{Estrutura e Desenvolvimento}

Para desenvolvermos uma pesquisa com a participação dos profissionais da educação, saúde, assistência social e da comunidade de pessoas com deficiência, para criação de propostas e intervenções, não poderíamos partir da concepção de uma metodologia científica tradicional. Assim, escolhemos a Pesquisa-Ação numa abordagem integral (PAI) que nos dá uma cobertura adequada dos acontecimentos sociais, levando em consideração não apenas um problema, mas um conjunto de valores subjetivos implicados no desenvolvimento da pesquisa, onde a imprevisibilidade e a subjetividade são levadas em consideração e geradas pela relação dos sujeitos com o objeto, relação esta, que não é artificial e não é produzida em laboratório para se verificar os resultados, mas está dentro das experiências vivenciadas.

Num processo de PAI é importante o cuidado com a técnica de coleta de dados, visto que, estes dados são gerados na vivência processual da pesquisa. Utilizamos texto, imagem e som para registrar os acontecimentos. Para tornar esta meta possível o registro de texto foi feito no MOODLE como Ambiente Virtual de Pesquisa (AVP) a partir das falas escritas nos fóruns, nos chat's, nos diários e nas atas. O registro de imagem e som foi capturado pela câmara filmadora permitindo uma cobertura mais próxima do real. Para Morin, A. (2004) “a máquina de filmar tem a vantagem de recriar a atmosfera... e pode ser estimulante para a ação e a reflexão sobre o comportamento dos atores pesquisadores". Outra característica, é que o vídeo consegue registrar o conjunto de ações humanas, que é complexo e difícil de ser descrito compreensivamente por um único observador enquanto ele se desenrola (LOIZOS, 2002).

Utilizamos também a fotografia para registrar a participação em eventos onde a máquina filmadora não era permitida ou de difícil manuseio, e para registrar situações de mudanças “antes” e “depois”. O uso de entrevista aconteceu em situações informais na fase preparatória e o questionário foi utilizado no rastreamento do levantamento das pessoas com deficiência, como ponto de apoio para a participante autóctone.

Para sistematização das ações, a pesquisa foi estruturada em dois blocos, que aconteceram simultaneamente e sem ordem, visto que, muitas ações foram geradas pelas discussões e realimentações, enfatizando uma das características da PAI, o vai e vem entre o discurso e a ação.

\section{Bloco I: Formação e Consenso}

Outro ponto importante na PAI é a formação dos participantes. Para Morin, A. (2004) o profissional que participa de uma pesquisa "está centrado no seu trabalho e no contexto em que o exerce, com vistas a melhorá-lo e a se auto-realizar... cada um quer aumentar seu saber prático,... e tornar-se um profissional que reflete sua própria ação.”. Assim, neste bloco propomos estratégias como: plenárias ${ }^{5}$, utilização do moodle como 
AVP e participação em simpósios, colóquios e congressos nacionais com o objetivo de trabalhar na formação do grupo, discutir os temas com a participação de todos, construir de forma coletiva e democrática e chegar a um consenso necessário para desenvolvimento do processo.

\section{Bloco II: Ações e Acompanhamentos}

Este bloco se centraliza nas ações práticas que aconteceram como resultado e simultaneamente ao bloco I. Na PAI existe uma relação de interdependência entre a ação e o discurso, para Barbier (2002) não há pesquisa sem ação. Assim, realizamos um levantamento em lócus das pessoas com deficiência no município Este instrumento de pesquisa tem um caráter descritivo e analítico. No primeiro caso, visa descrever sumariamente aspectos da condição social e econômica, autonomia, participação, freqüência e permanência escolar das pessoas com deficiência nas escolas públicas regulares, com destaque para o uso das TA e ações dos órgãos públicos no processo de inclusão.. Em segundo lugar, a análise deste conjunto descritivo consistirá da reflexão sobre os dados coletados com as bases teórico-metodológicas formalizadas na pesquisa, com vistas, em conseqüência, a contribuir com as ações e estratégias, para a efetivação de práticas consistentes, instrumentalizadas cientificamente, e com compromisso social na proposta de inclusão das pessoas com deficiência.

\section{Resultados e Discussões}

Em 1988 é publicada a primeira Lei americana P.L. $100-407^{6}$ ressaltando a importância dos serviços das TA para as pessoas com deficiência, levando em consideração que mesmo com tantas tecnologias disponíveis, elas não tinham as características de acessibilidade. $\mathrm{Na}$ época foram detectados dois problemas principais: Primeiro, faltam às pessoas com deficiência e pais, irmãos, amigos, professores, conselheiros e empregadores, conhecimento e formação na utilização dos serviços de suporte e tecnologia. Nas discussões e estudos em plenárias, da realidade local, concluímos que após 20 anos, ainda nos encontramos nesta situação. Enquanto países como Itália, Espanha, Suécia e Estados Unidos da América tiveram avanços na legislação e na prática.

Segundo, não há sistema abrangente para ajudar pessoas com deficiência a adquirirem tecnologia e garantir que essa tecnologia seja adequada ou personalizada para satisfazer as necessidades exclusivas de um indivíduo ou circunstâncias, ou para proporcionar a formação de atualização, substituição ou reparação de tais tecnologias. Com base nos dados levantados concluímos que 69\% das pessoas com deficiência entrevistadas no município não têm qualquer tipo de acesso ás tecnologias classificadas como TA e que apenas 3\% tem acesso a algum tipo de TA nas escolas públicas regulares.

No Brasil o Ministério da Ciência e Tecnologia (MCT), coloca como suas as seguintes prioridades de incentivo ao desenvolvimento de TA no país: promover a realização de seminários regionais sobre o tema; fazer um levantamento nacional para identificação e caracterização das instituições que produzem TA; a partir do material coletado na identificação nacional, criar um Banco de Dados Nacional para consulta das TA existentes no país; fortalecer a pesquisa e o desenvolvimento desse tipo de tecnologia por todo o Brasil; apoiar as Universidades e os Centros de Pesquisa no desenvolvimento de TA; desenvolver normas nacionais de TA, ainda inexistentes no país; incentivar a produção dessas tecnologias pela indústria nacional; promover a disseminação das tecnologias e celebrar parceria, por meio de um Termo de 
Compromisso de Execução com as unidades de pesquisa vinculadas ao MCT para dar início à pesquisa e desenvolvimento dessas tecnologias nas mais variadas áreas.

Em 1973 o MEC cria o Centro Nacional de Educação Especial (CENESP) para impulsionar as ações de inclusão da educação especial no Brasil, mas baseia-se na filosofia assistencialista com ações isoladas. A Constituição Federal de 1988 nos artigos 205, 206 e 208 assume a Educação como direito de todos e o atendimento educacional especializado preferencialmente nas escolas regulares. Esta posição é reforçado pelo Estatudo da Criança e Adolescente (1990), pela Declaração Mundial de Educação para Todos (1990) e a Declaração de Salamanca (1994). Estes documentos vão influenciar a construção da Política Nacional de Educação Especial no Brasil (1994).

O Grupo de Trabalho do $\mathrm{MEC}^{7}$ conclui que esta política não conseguiu criar práticas educacionais que valorizassem as diferenças nas classes regulares, e em 1999 o Decreto $n^{\circ} 3.298$ define a educação especial como uma modalidade transversal a todos os níveis e modalidades de ensino, enfatizando a atuação complementar da educação especial no ensino regular.. E só em 2003 o MEC cria o Programa Educação Inclusiva visando instituir a educação inclusiva no sistema educacional brasileiro. A Língua Brasileira de Sinais é garantida através da Lei $n^{\circ}$ 10.436/02, mas no município, mesmo os profissionais formados recentemente, não receberam a formação da disciplina de Libras, assim como o sistema de braile, dificultando a materialização da legislação já constituída. No levantamento do município 60\% dos surdos não sabem Libras, o que se constituiu uma prioridade nas ações propostas.

Foi com a Lei 10.098 que o Brasil estabeleceu as primeiras normas e critérios para fomentação das TA no processo de inclusão das pessoas com deficiência. O Instituto de Tecnologia Social (ITS Brasil) em parceria com a Secretaria de Ciência e Tecnologia para a Inclusão Social (Secis) e o Ministério da Ciência e Tecnologia (MCT) desenvolveu um estudo identificando as instituições brasileiras que se dedicam à pesquisa e desenvolvimento tecnológico para pessoas com deficiência. A criação do Portal Nacional de TA e propostas de criação de Centros de Pesquisa de TA em Universidades como a Universidade Federal do Rio de Janeiro (UFRJ) com os projetos MOTRIX, FENIX e DOSVOX são ações desenvolvidas para viabilizar as condições para uma educação inclusiva utilizando as potencialidades das TA.

O Catálogo Nacional de Produtos de Tecnologias Assistivas do Brasil já possui em seu cadastro 308 produtos desenvolvidos por instituições brasileiras, na sua maioria instituições acadêmicas do Rio Grande do Sul, Santa Catarina, Minas Gerais, São Paulo e Rio de Janeiro. Elas representam 59\% de todas as pesquisas desenvolvidas na área de TA no Brasil Mas poucos deles são desenvolvidos para comercialização por falta de uma política de incentivo e socialização, e na prática, poucas pessoas com deficiência se beneficiam com as pesquisas realizadas. Os produtos ficam armazenados nas instituições segundo o estudo produzido pelo ITS, com orientação do Ministério de Ciência e Tecnologia, que fornece um retrato da pesquisa em TA no Brasil.

A dificuldade dos estudos com as TA vêm de suas características individuais, que as tornam de difícil socialização e de alto custo. O fundo de universalização dos serviços de telecomunicações (FUST) instituído pela lei $\mathrm{n}^{0} 9.998$, de 17 de agosto de 2000, tem por finalidade proporcionar recursos destinados ao cumprimento de obrigações de universalização de serviços de telecomunicações ${ }^{8}$ entre outros objetivos; visa também o fornecimento de acessos individuais e equipamentos de interface a instituições de assistência pessoas com deficiência carentes, mas para que estes recursos sejam solicitados é necessário um estudo especifico para cada escola e para cada aluno, 
com um projeto que viabilize e atenda um maior número possível de educandos, que segundo a Resolução número 2/2001, esta é uma atribuição das escolas.

Com isto concluímos a necessidade da criação regional de Centros de Pesquisa de Tecnologia Assistiva para viabilizar o processo de inclusão das pessoas com deficiência nas escolas públicas regulares, acompanhado por uma equipe multidisciplinar e a inclusão de LIBRAS como a segunda língua para os falantes no currículo de Ensino Fundamental I e II.

\section{Conclusões:}

Compreendemos que a proposta do uso das TA no processo de inclusão das pessoas com deficiência desenvolvida a partir da PAI com a participação de diferentes profissionais da estrutura social, permite proposições mais reais e concretas para solucionar as dificuldades geradas pela complexidade deste processo que envolve “coisas” tangíveis e intangíveis (Arendt, 2006).

As TA podem ajudar estudantes com dificuldades funcionais a participarem efetivamente das oportunidades na educação É necessário entretanto, entendermos o significado que determina o tipo de relação que se estabelece com as pessoas com deficiência, e Sassaki (2009: 8 - 11) discute esta relação ao falar sobre a problematica da terminologia usada para identificar as pessoas com deficiência, enfatizando que o grau de relação da comunidade, vai definir a forma como eles serão tratados e chamados. A questão é que a tal forma corresponde uma política de sentido, uma posição política, um modo cultural, estrutural e arraigado.

O processo de inclusão das pessoas com deficiência a partir das TA não é unicamente um processo de inclusão digital, pois isto seria desconsiderar e empobrecer as potencialidades e importância que este processo vai ter na vida destes sujeitos, visto que, para muitos, o acesso às TA não é uma simples escolha, significa a única opção de retorno ou entrada no mundo da comunicação ${ }^{9}$ ou mobilidade. $\mathrm{O}$ que se traduz não apenas em uma inclusão digital, mas possibilidades de inclusão educacional e social. Compreende-se que inclusão de pessoas com deficiência já traz estas três ordens imbricadas com acontecimentos imprevisíveis e que podem existir ou não simultaneamente. Assim, a importância e o lugar das TA no processo de inclusão das pessoas com deficiência só pode ser definido a partir das diferenças.

Com esta compreensão, entendemos que inclusão de pessoas com deficiência parte de uma base democrática que se prolifera numa relação risomática de princípios. Portanto, inclusão de pessoas com deficiência é um conjunto de princípios democráticos que vão permitir o exercício da cidadania, da autonomia e do direito à escola, ao lazer, à família, ao conhecimento, enfim, ao empoderamento dentro de uma sociedade sem preconceitos e com acessibilidade

Mesmo assim, o sistema de educação brasileiro não possui procedimentos e planejamento de formação de profissionais para atender as escolas públicas e, como visto em Madre de Deus e cidades próximas, as ações de inclusão não usam as potencialidades das TA no processo de inclusão das pessoas com deficiência nas escolas públicas.

Percebe-se aqui, que nesta pesquisa, não estamos propondo algo que já não esteja garantido. Este entrave, a distância entre o que a Lei determina e o que de fato está acontecendo nas escolas foi a nossa preocupação. Não há uma materialização das Leis. 
Assim, no Brasil, verifica-se um avanço nas Leis que não é acompanhado pelas ações e movimentos de inclusão nos espaços educacionais. As políticas públicas que visam a inclusão das pessoas com deficiência nas escolas públicas a partir do uso das TA são deficientes e de difícil execução, mesmo que o resultado de pesquisas em todo o mundo mostrem que as TA podem ajudar as pessoas com deficiência, as escolas, as famílias e a sociedade no processo inclusivo

\footnotetext{
${ }^{1}$ Documento elaborado pelo Grupo de Trabalho nomeado pela Portaria Ministerial $n^{\circ}$ 555, de 5 de junho de 2007, prorrogada pela Portaria ${ }^{\circ}$ 948, de 09 de outubro de 2007.

${ }^{2}$ A memória é o saber discursivo, a memória do dizer. Ё o que foi dito e o que é dito a respeito de um assunto. É o que foi dito, mas, com o passar do tempo, esquecemos como foi dito, por quem e em que circunstância, ficando como um já dito, sobre o qual os nossos sentidos se produzem (apud. MARQUEZAN, 2009: 30)

${ }^{3}$ Public Law 101-336

${ }^{4}$ Sistema unificado de técnicas, isoladas sobre um planeta informado e permitindo ações igualmente globais... Havia, com o imperialismo, diversos motores, cada qual com sua força e alcance próprios... Hoje haveria um motor único, que é, exatamente, a mencionada mais-valia universal. (M. Santos, Por uma outra globalização, 2009: 29).

${ }^{5}$ Encontros presenciais para estudos, discussões e avaliações dos materiais coletados e produção de relatórios; para elaboração de consensos, proposições e discussões teóricas.

${ }^{6}$ Technology Related Assistance for Individuals with Disabilities Act (Tech Act)

${ }^{7}$ Nomeado pela portaria $n^{\circ} 555 / 2007$ prorogada pela portaria $n^{\circ} 948 / 2007$ entregue ao ministro da Educação em 07 de janeiro de 2008.

${ }^{8}$ Art 80 da Lei No 9.472 - de 16 de julho de 1997 - DOU DE 17/7/97.

${ }^{9}$ Abrange as línguas, a visualização de textos, o Braille, a comunicação tátil, os caracteres ampliados, os dispositivos de multimídia acessível, assim como a linguagem simples, escrita e oral, os sistemas auditivos e os meios de voz digitalizada e os modos, meios e formatos aumentativos e alternativos de comunicação, inclusive a tecnologia da informação e comunicação acessíveis. (Declaração dos Direitos da Pessoa com Deficiência )
}

\section{Referências Bibliográficas}

ARENDT, Hannah. A condição humana. Trad. Roberto Raposo. 10 ed. Rio de Janeiro: Forense Universitária, 2008.

O que é política? Trad. Reinaldo Guarany. 6. ed. Rio de Janeiro: Bertrand Brasil, 2006. 240p.

BARBIER, René. A pesquisa-ação. Trad. Lucie Didio. Brasília: Plano Editora, 2002. 157p.

BAUER, M. W. \& Gaskell, G. (Orgs.) Pesquisa qualitativa com texto, imagem e som: um manual prático. (P. A.Guareschi, Trad.). Petrópolis: Vozes, 2002.

BONETI, Lindomar Wessler. Políticas públicas por dentro. 2. ed. Ijuí: Unijuí, 2007. 96p.

BRASIL. Estatuto da Criança e do Adolescente no Brasil. Lei n. 8.069 de 13 de julho de 1990.

Ministério da Educação. Secretaria de Educação Especial. Política Nacional de Educação Especial Na Perspectiva da Educação Inclusiva. Brasília: MEC/SEESP, 2007. 
. Resolução CNE/CEB 2/2001.Conselho Nacional De Educação. Câmara de Educação Básica.. Diário Oficial da União, Brasília, 14 de setembro de 2001. Seção 1E, p. 39-40.

Lei $\mathbf{N}^{\circ}$ 9.394, de 20 de dezembro de 1996. - Estabelece as diretrizes e bases da educação nacional. 27 p.

Convenção Sobre os Direitos das Pessoas com Deficiência. Sistema Nacional de Informações sobre Deficiência -SICORDE. 2007.

Decreto $\mathbf{N}^{\circ}$. 5.296 de 2 de dezembro de 2004. Regulamenta as Leis nos 10.048 , de 8 de novembro de 2000, que dá prioridade de atendimento às pessoas que especifica, e 10.098, de 19 de dezembro de 2000, que estabelece normas gerais e critérios básicos para a promoção da acessibilidade das pessoas portadoras de deficiência ou com mobilidade reduzida, e dá outras providências.

HITCHCOCK, C., Meyer, A., Rose, D, \& Jackson, R. (2002). Providing Access to the General Education Curriculum. Universal Design for Learning. Teaching Exceptional Children, 35(2), 8-17.

LIMA JR, A. Tecnologias Inteligentes e Educação: currículo hipertextual. Rio de Janeiro: Quarter; Juazeiro, BA: FUNDESF, 2005.

MARQUEZAN, Reinoldo. O Deficiente no discurso da Legislação. Campinas/SP: Papirus, 2009. (Série Educação Especial)

MONTOAN, M.T.E. Inclusão Escolar. O que é? Por que? Como Fazer?. 2 ed. São Paulo: Moderna, 2006.

MORIN, Andre. Pesquisa-ação Integral e Sistêmica: uma antropopedagogia renovada. São Paulo: DP\&A, 2004.

SASSAKI, R K. Inclusão: Construindo uma sociedade para todos. 7.ed. Rio de Janeiro: WVA, 1997. 176p.

Como chamar as pessoas que têm deficiência? In: Sociedade Brasileira de Ostomizados, ano I, n. 1, $1^{\circ}$ sem. 2003, p.8-11.

SANTOS, Milton. Por uma outra globalização: do pensamento único à consciência universal. 18. ed. Rio de Janeiro: Record, 2009

UNESCO. Declaração de Salamanca e linha de ação sobre necessidades educativas especiais. Brasília, CORDE, 1994 